\title{
REFLETINDO SOBRE A PRÁTICA DE CONJUNTOS MUSICAIS NO CURRÍCULO UNIVERSITÁRIO
}

\author{
Reflecting on ensemble practices in the university \\ curriculum
}

\author{
JosÉ AlBERTO SALGADO \\ Escola de Música - Universidade Federal do Rio de Janeiro \\ zeal.musica@gmail.com \\ PEDRO ARAGÃo \\ Instituto Villa-Lobos - Universidade Federal do Estado do Rio de Janeiro \\ pmaragao@gmail.com
}

\begin{abstract}
Resumo: Apresenta-se uma reflexão dialógica sobre o trabalho em cursos universitários de Licenciatura e Bacharelado em Música, especificamente na atividade curricular de conjuntos integrados por estudantes. As atividades nessa faixa do currículo recebem denominação variada - sendo "Música de Conjunto" e "Prática de Conjunto" as denominações genéricas mais comuns. Os autores fizeram uso da correspondência eletrônica (e-mail) para a construção dialógica do ensaio, recorrendo a experiências de docência e de pesquisa etnográfica em uma universidade pública do Rio de Janeiro, e aludindo a referências multidisciplinares. A presente reflexão partilhada produziu sugestões e questões úteis ao planejamento didático e à avaliação, com que os autores almejam contribuir para a continuidade de análises, ações e diálogos nesse setor da educação musical universitária.
\end{abstract}

Palavras-chave: Prática musical em conjuntos. Formação musical universitária. Diálogo e reflexão

\begin{abstract}
The authors write in dialogue, to reflect on music education at the university, specifically addressing the curricular activity of students in music ensembles. Activities in this sector may receive different course titles - "Ensemble practice" and "Ensemble music" being the most frequent. The authors have made use of electronic mail (e-mail) to compose the dialogical exchange, and resorted to experiences in teaching and doing ethnographic research at one public university in Rio de Janeiro, while pointing to multidisciplinary references. The shared analysis presents ideas and questions of relevance to pedagogical planning and assessment, with which the authors aim to contribute to further analyses, actions and dialogues in this sector of Music curricula in Higher Education.
\end{abstract}

Keywords: Practice in music ensembles. Music in Higher Education. Dialogue and reflection. 


\section{PREÂMBULO}

Em que consiste o trabalho de fazer música "em conjunto" nos cursos de graduação em Música? Como se têm organizado essas práticas, e que possibilidades adicionais se apresentam no cenário acadêmico contemporâneo? Que problemas principais enfrentam docentes e estudantes nesse setor do currículo?

Este ensaio apresenta uma reflexão dialógica sobre esse tipo de trabalho musical, que ocorre de modo formalizado e tem papel formativo. As atividades nessa faixa do currículo recebem denominação variada, conforme verificamos por uma enquete junto a colegas de universidades brasileiras sendo "Música de Conjunto" e "Prática de Conjunto" as denominações genéricas mais comuns ${ }^{1}$. Sem pretensão de responder de modo acabado às perguntas esboçadas acima, nosso intuito é, antes, o de levantar elementos para mais análises dos sujeitos que atuam diretamente nessas disciplinas. Entendemos que estas, talvez por se identificarem tão fortemente com o domínio da prática, com sua lógica intrínseca - pouco afeita à investigação das próprias premissas (Bourdieu, 2002) -, têm recebido pouco tratamento reflexivo na literatura de educação musical.

Tomando como ponto de partida experiências de docência - no caso de Aragão - e de pesquisa etnográfica (Salgado, 2005) com a Prática de Conjunto em uma universidade pública do Rio de Janeiro, e aludindo a referências multidisciplinares (p. ex., Freire, 1970; Travassos, 2005; Hennion, 2002), os autores mantiveram correspondência eletrônica durante um periodo de seis meses, acrescentada de três encontros para discussão presencial, e revisão, a fim de construir nesse processo uma escrita em forma de diálogo.

Praticada historicamente como gênero de discurso (Bakhtin, 1987), a forma do diálogo tem veiculado saberes e reflexões sobre diferentes práticas musicais, suas conceituações e sua transmissão. Temos como alguns exemplos marcantes, e bem distintos entre si: a coletânea de diálogos e artigos Music grooves, em que os pesquisadores Charles Keil e Steven Feld discutem suas experiências de campo, teorizações e trajetórias de formação (Keil; Feld, 1994); o famoso manual de contraponto do século XVIII, Gradus ad

\footnotetext{
${ }^{1}$ Ainda que não exaustiva, a enquete revelou que a disciplina "Prática de Conjunto" aparece, com pequenas variações de nomes, na maior parte das grades curriculares dos cursos de música das universidades federais brasileiras. Com este nome, ela aparece como eixo central dos cursos de música popular na UNIRIO, na UFPel e na UFRGS. No bacharelado em Música Popular da UNICAMP, a disciplina aparece como "Prática Instrumental". No bacharelado em Música Popular da UFMG, a disciplina aparece sob dois nomes diferentes: "Tópicos Especiais em Música de Conjunto" e "Práticas Interpretativas", voltadas para formações menores, e "Grandes Grupos Instrumentais", voltada para formações maiores, como big bands. A disciplina também aparece com o nome de "Prática de Conjunto" ou pequenas variantes nos seguintes cursos de Licenciatura: UFMA, UFCA, UFC, UFU, UFBA, UFJF, UFPG (com a designação "Prática de Conjunto Musical"), UFG (com a designação "Conjunto Musical”), UFRN, UFCG, UFES (com a designação "Música de Conjunto"). Este levantamento foi realizado por consulta a colegas, via correio eletrônico, e através de pesquisa de matrizes curriculares disponíveis na internet.
} 
Parnassum, do compositor Johann Fux, em que se representa uma série de encontros pedagógicos entre um mestre e um aprendiz (Fux, 1971); um outro livro, muito lido em cursos de Licenciatura em Música, O Ouvido pensante, em que o compositor R. M. Schafer representa seus diálogos com estudantes, em oficinas de educação musical (Schafer, 1991); e os diálogos sob o título Paralelos e paradoxos (Barenboim; Said, 2002), em que o regente Daniel Barenboim e o historiador Edward Said discutem suas visões estéticas e politicas em torno da prática musical, com ênfase na prática sinfônica e na música de concerto.

Antes mesmo de sua edição e publicação em forma escrita, processos de interlocução mostram-se fundamentais em pesquisas empíricas que se dedicam a investigar questões sobre realização, aprendizagem e significação de "música" em contextos diversos (p. ex. Green, 2001, 2008; Prass, 2009; Salgado et al., 2014). Em muitas pesquisas qualitativas em educação musical, a interlocução ocorre principalmente como entrevistas com colegas e/ou estudantes, e tem se constituído como fonte de dados obtidos "em campo", como se verifica em diversos artigos publicados na Revista da ABEM (p. ex. Arroyo, 2000; Santos, 2012).

Aqui, nosso plano foi partir da experiência docente e investigativa para tratar - em parceria e por escrito - do trabalho educativo que se realiza diretamente como prática musical em conjuntos. $O$ objetivo é que o intercâmbio reflexivo e o levantamento de questões sejam úteis à continuidade de ações e diálogos entre docentes e discentes envolvidos nessa parte da formação universitária.

\section{O DIÁLOGO}

José Alberto Salgado: Ao sugerir que tratássemos do que é feito e pensado em rotinas de "Prática de Conjunto" na universidade, você indicou um tema que provavelmente interessa a muita gente. A esta altura, é possível que todos os currículos de Música, no ensino superior brasileiro, incluam, com variações do título, esta disciplina; e, neste caso, dizemos "disciplina" apenas por uso flexível do jargão educacional, já que a Prática de Conjunto ocorre como trabalho muito adaptável às particularidades de cada grupo inscrito, do professor que o orienta e do repertório escolhido. Não se pode dizer que exista forte padronização de materiais, conceitos ou procedimentos adotados entre instituições; assim como não se encontra um corpus de estudos empíricos, teóricos ou historiográficos correspondente. O nome, aliás, diz exatamente: trata-se de uma prática, organizada como atividade curricular, e que provavelmente tem, para os estudantes, uma correspondência das mais reconhecíveis com a atividade profissional, no sentido de preparação e realização de uma performance coletiva, em público.

Seria interessante então começarmos a ouvir como é que um professor diretamente envolvido com tal prática caracteriza este tipo de trabalho. 
Pedro Aragão: Considero a "Prática de Conjunto" (PC) como uma das mais ricas e desafiadoras disciplinas no âmbito do ensino musical universitário. Ela se diferencia do espectro geral de matérias de um curso de graduação por uma série de fatores. Em primeiro lugar, ela depende fundamentalmente da atuação prática do aluno em sala de aula. Se é certo que, mesmo em disciplinas consideradas "teóricas" - como harmonia e história da música, por exemplo -, novas metodologias proponham cada vez mais dinâmicas dialógicas, com o abandono do sistema clássico, onde o professor fala e os alunos escutam (como na metáfora do depósito bancário, proposta por Paulo Freire (1970) - a Prática de Conjunto não existe sem a intervenção prática dos estudantes. Em outras palavras, como professor de história da música, posso propor aulas dialógicas com ampla participação dos alunos. Se estes, entretanto, permanecerem calados ou inativos, a aula acontecerá da mesma forma. O mesmo não acontece na Prática de Conjunto.

Em segundo lugar, como você bem disse, não há padronização de procedimentos nas universidades brasileiras, e o espectro de metodologias utilizadas é bastante heterogêneo. Esta é sem dúvida uma das riquezas da disciplina: ela assume matizes e variantes que dependem de uma série de fatores, tais como particularidades de conjuntos, repertórios, presença ou ausência de material pré-organizado e nivel técnico dos alunos, dentre outros fatores. Este é um ponto que julgo dos mais importantes, e que podemos desenvolver posteriormente.

Em terceiro lugar, a Prática de Conjunto normalmente pressupõe uma apresentação pública ao final do semestre: seu resultado é usualmente compartilhado de alguma forma com o público que está fora da sala de aula. Aqui também a gama destas apresentações varia muito, mas em geral elas podem abranger desde um público restrito à universidade (alunos, professores, funcionários) até um público mais amplo. Continuando a comparação com outras disciplinas, posso ministrar uma aula de harmonia ou de percepção musical perfeitamente encerrado entre quatro paredes, do início ao fim do curso com os alunos. A Prática de Conjunto, entretanto, implica normalmente algum movimento "para fora" da sala de aula, na forma de alguma apresentação que é resultado final do trabalho realizado ao longo do semestre. É neste ponto que ela se assemelha à atividade profissional, como você salienta. Da mesma forma que qualquer músico atuante, a apresentação de uma PC é o momento em que alunos e professores estão "expostos", para o bem ou para o mal... A fronteira da sala de aula foi rompida e os resultados e produtos finais podem ser conferidos por aqueles que não frequentaram o curso. Este "produto" final é sem dúvida outra característica que distingue a PC do âmbito de outras disciplinas no campo da música.

JAS: A caracterização inicial está clara e instiga a pensar em cada um dos fatores, assim como em possíveis relações entre eles. Durante pesquisa 
etnográfica com estudantes do IVL-UNIRIO, também observei a atividade curricular da Prática de Conjunto como uma série de encontros semanais que logo eram assumidos como ensaios sobre um repertório. Ao final do período letivo, esse repertório era apresentado em público, numa mostra coletiva em que tomavam parte todos os grupos inscritos naquela disciplina. É a sua imagem de uma fronteira que se desfaz entre sala de aula e espaço público, e que também propicia contato direto entre os conjuntos organizados a cada semestre. Durante aqueles dias com aspecto de festival, toda uma produção musical é exposta entre pares e a um público mais amplo. Diante da programação intensa, tive a impressão de que poderia haver mais desdobramentos com interesse para a vida universitária e artística - por meio de registro audiovisual, exibição com análises, autoavaliação comentada, por exemplo. E agora com o trabalho docente, movido por uma metodologia que promove a escrita analitica, penso também na possibilidade de os estudantes manterem diários sobre os ensaios e apresentações, com produção de relatório-sintese sobre a montagem de cada repertório ${ }^{2}$. Enfim, uma ideia a mais, entre tantas que provavelmente ocorrem aos professores envolvidos com essa disciplina pouco canônica e muito mais afeita à variedade de métodos, que você destaca como segundo fator.

$\mathrm{E}$, com esses traços sujeitos a mais discussão e desenvolvimento, sublinho ainda o seu primeiro ponto, que revela - com a surpresa das coisas muito vividas e nem sempre teorizadas - a dependência direta da atuação discente para os resultados dessa disciplina. O que você disse sobre a "intervenção prática do estudante" leva a considerar problemas e oportunidades no manejo de técnicas entre sujeitos com habilidades e experiências distintas. Leva a considerar também a importância das atitudes e dos comportamentos - que se mostram, que se problematizam - durante todo o processo de trabalho em conjunto. Dois exemplos bem distintos, da mesma pesquisa que mencionei: conheci estudantes que, já no ato de sua inscrição numa PC, tinham a intenção de formar um conjunto que se mantivesse ativo para além do âmbito da disciplina; assim como encontrei o caso de um estudante que, ao cursá-la, enviou gravação de suas composições e as partes escritas para os colegas do conjunto, comparecendo apenas aos dois ensaios que antecediam a apresentação semestral - ele argumentou que assim buscava reproduzir condições de trabalho encontradas no "mundo real". Só aí, em rápidas linhas, já estamos apontando para a questão da diferença e da negociação em dimensões de técnica, de ética, de organização social, não é? Se por um lado a particularidade dos processos pode ser contada como pressuposto a cada início de percurso, por outro lado vem a curiosidade de saber se estamos adotando algum tipo de parâmetro ou orientação constante para tratar com as diferenças que se apresentam.

\footnotetext{
${ }^{2}$ Esse registro acadêmico e reflexivo seria mais uma das formas disponíveis para se teorizar sobre a prática e exercitar a narrativa sobre processos de atividade musical, promovendo também a comunicação entre pares e outros interessados.
} 
PA: Sim, creio que você toca em um ponto fundamental: a questão da diferença. Este é sem dúvida um dos grandes temas da atualidade e vem sendo trabalhado em vários planos, que vão desde um prisma epistemológico - como a crítica de Gutierrez à "identidade excessiva" dos tempos atuais, que seria responsável pela geração de discursos autoritários e redutores da complexidade do mundo social (Gutierrez, 2009) - até o plano político - com o fomento a ações inclusivas na educação, tais como as politicas de cotas e de universalização do acesso ao ensino superior no Brasil. No plano dos estudos acadêmicos em música, é óbvio que a etnomusicologia vem há muito trabalhando com a questão da alteridade - o espectro é amplo, mas destacaria aqui trabalhos que versam sobre a institucionalização da desigualdade social no ensino superior (Travassos, 2005) e sobre novos modelos de pesquisa-ação focados em uma perspectiva de engajamento político que busca transformações sociais (Araújo, 2006), por serem transversais ao nosso tema. No campo da educação musical, o tema da diferença ganhou novo fôlego a partir da lei que torna obrigatório o ensino de música nas escolas, com amplas discussões sobre a adoção de modelos que abranjam a pluralidade cultural e a diversidade (Queiroz, 2004; Nwezi, 2012).

No âmbito do ensino superior em música, penso que uma reflexão sobre a disciplina Prática de Conjunto - com suas várias possíveis denominações, adotadas em diferentes universidades - nos permite teorizar sobre a diferença a partir de vivências práticas do dia a dia de alunos e professores. Talvez seja oportuno voltarmos agora ao segundo ponto exposto em minha fala inicial sobre as particularidades da disciplina: como dissemos, a PC se caracteriza justamente pela heterogeneidade de procedimentos e metodologias adotadas. Esta heterogeneidade - somada ao nosso pressuposto de que a disciplina depende essencialmente do que chamamos de "atuação prática do estudante" - é terreno fértil tanto para o surgimento de conflitos, alteridades e mesmo violências simbólicas nas relações professor-aluno e aluno-aluno, quanto para o surgimento de vivências realmente enriquecedoras de aprendizado a partir das diferenças.

Partindo desta constatação, podemos tentar mapear as diferentes formas de realização de PCs em âmbito universitário com o intuito de melhor entendermos essas diferenças - mesmo correndo o risco de cairmos em algum reducionismo. Dada a multiplicidade de procedimentos encontrados nas universidades, é difícil propor uma categorização "fechada". Mas, em geral, uma análise da oferta de disciplinas ligadas à PC, no início de cada semestre universitário, já nos permite uma primeira tentativa de mapeamento.

Um primeiro tipo de PC bastante comum é aquela com ênfase em instrumentação e repertórios predefinidos: neste grupo teríamos formações consideradas "tradicionais", tais como orquestras, big bands, grupos corais, pequenos ensembles (quartetos de cordas, quartetos de saxofone), dentre outros. Justamente por seu caráter tradicional, tendem a usar um "cânone" 
de repertório já consagrado e fartamente editado - arranjos para big bands, peças sinfônicas, peças corais, dentre outros. Normalmente, ao abrir a disciplina, o professor já tem definida a instrumentação que utilizará e o repertório a ser trabalhado, não havendo muito espaço para mudanças a partir da interlocução com os alunos. Outros dois fatores caracterizam este tipo de PC: em geral o professor assume uma perspectiva mais prescritiva do que dialógica - parte-se do pressuposto de que o professor já sabe de antemão quais "sons" quer retirar daquele conjunto, os "sons certos" associados à orquestra sinfônica, à big band e a outros grupos assemelhados. Finalmente, espera-se que os alunos tenham, se não um alto nível técnico na execução de seus instrumentos, pelo menos um nível intermediário que permita a execução destes sons. Ou seja, o nível técnico já é um diferenciador a priori, definindo aqueles que podem ou não participar da PC. A instrumentação é outro diferenciador: cavaquinistas não podem se inscrever em orquestras sinfônicas, assim como violinistas não podem se inscrever em big bands: os exemplos são diversos.

Um segundo tipo de PC igualmente comum é aquela que se define a partir de gêneros musicais comercialmente consagrados - muitas vezes anunciada também como "oficina": "Oficina de choro", "Prática de bossanova", "Prática de jazz" seriam alguns exemplos. Ainda que assentadas sobre repertórios também "canônicos", em geral se observa uma maior flexibilidade no que se refere à escolha de repertório específico e instrumentação utilizada. É claro que isso depende muito da diretriz proposta pelo professor: este pode definir, a priori, que trabalhará com um trio de piano, baixo e bateria e com determinadas peças de Cole Porter em sua prática de jazz, por exemplo. Entretanto, se cada um destes gêneros "consagrados" pode ser associado a uma instrumentação específica (violão, pandeiro e cavaquinho ao choro; piano, baixo e bateria ao jazz; triângulo, sanfona e zabumba ao forró, dentre outros), é muito comum vermos PCs que não estabelecem um instrumental específico a priori. Assim, é possivel encontrar, no dia a dia das práticas de conjunto universitárias, cavaquinistas frequentando PCs de jazz, trompistas em PCs de choro, guitarristas em PCs de forró, dentre outros. Ou seja, em geral a instrumentação não é um diferenciador no acesso do estudante à disciplina - ainda que haja exceções, naturalmente.

No que se refere ao repertório, é claro que a associação da PC com gêneros musicais predefinidos já indica um corpus de músicas e canções a serem trabalhadas. Aqui o espectro é mais uma vez heterogêneo: se em geral o professor pode predefinir um repertório, é comum também haver espaço para a proposição de peças específicas por parte dos alunos - desde que estas pertençam ao gênero proposto pela $\mathrm{PC}$. Na maioria das vezes, o material didático utilizado é baseado em partituras em formato melodia e cifra - lead sheet, como denominam os norte-americanos, formato que se consagrou como padrão no mercado editorial associado à música popular. Tendo este material como base, a atuação do professor pode variar em um âmbito que 
vai desde uma perspectiva mais prescritiva (ele estabelece aspectos como instrumentação, arranjos, "levadas", dinâmicas, dentre outros), passando por uma perspectiva mais dialógica (com os aspectos anteriormente mencionados sendo estabelecidos entre alunos e professor), indo até uma perspectiva de não intrusão (com o professor deixando essas decisões totalmente a cargo dos alunos). Esses três vértices podem ser continuamente combinados ao longo de uma mesma PC - e obviamente há muitas nuances entre eles.

Sob o ponto de vista da diferença, este tipo de PC apresenta desafios muito maiores, quando comparados ao modelo anteriormente apresentado. Se normalmente orquestras e big bands já estabelecem um "filtro" para a entrada de alunos - o nivel de proficiência no instrumento -, é comum termos, neste segundo modelo, alunos de diferentes níveis em uma mesma prática. Esta diferença de nivel pode se relacionar não só com o grau de proficiência no instrumento, mas com outros aspectos, como o conhecimento específico daquele gênero musical, facilidade/dificuldade de improvisação, dentre outros.

Ainda que aparentemente não existam estatísticas sobre as diferentes modalidades de Práticas de Conjunto nas universidades brasileiras, minha experiência como professor me leva a crer que estes dois modelos apresentados se constituem como os mais representativos no dia a dia do ensino superior. Como elo comum entre eles está o fato de que o professor é quase sempre o proponente da prática a ser trabalhada: em outras palavras, disciplinas como "Prática de Orquestra", "PC de jazz", "Oficina de choro" e "Prática de bossa-nova" já aparecem prontas no quadro de disciplinas oferecido aos alunos no início do semestre.

Para além destes dois modelos, há outros tipos de PCs que são baseadas em proposições dos alunos: práticas voltadas para trabalhos de composição, arranjo ou repertórios específicos propostos pelos estudantes. Em geral são verificados em menor número, porque sua existência é sujeita a uma série de complicadores que vão desde aspectos burocráticos relacionados com ofertas de disciplinas até o processo de negociação com os professores - por partirem da ação dos alunos, estas PCs podem, potencialmente, subverter a lógica "professor-aluno", ainda tão disseminada em nosso cotidiano.

Por fim, é necessário salientar uma vez mais que tudo o que foi exposto pode ser visto apenas como um esboço de mapeamento de práticas de conjunto no ensino superior e das "diferenças" que se apresentam entre elas. Mesmo com essa ressalva, penso que este esboço já levanta questões relevantes.

JAS: Com esse mapeamento, temos então uma articulação de dois parâmetros bem expostos, que vão caracterizar o trabalho em cada conjunto: por um lado, o modo como se constitui o repertório e se define a instrumentação; por outro, o modo como se constitui uma relação de trabalho 
curricular entre professor e estudantes. A partir daí, pode-se observar uma variedade de organizações entre os polos de predeterminação completa e negociação aberta - quanto a repertório e instrumentação - e os polos de direção centralizada (pelo professor) e gestão coletiva (pelos estudantes), quanto às muitas decisões envolvidas na preparação e realização da performance musical. E certamente a variedade empírica ${ }^{3}$ será grande e digna de detalhamento.

A meu ver, torna-se importante detalhar os diferentes processos, principalmente numa educação universitária que procure promover uma capacidade analitica sobre as relações intersubjetivas no trabalho musical, assim como sobre outras características e sobre os resultados de cada processo. A breve análise que estamos colocando em jogo seria útil como um ponto de partida para as descrições e análises dos participantes em cada caso, assim como em pesquisas abrangendo um número maior de conjuntos.

Não é questão de eleger aqui um modelo como ideal para a ação com todos os conjuntos. Ao contrário, essas análises podem fomentar a reflexão dos participantes sobre suas práticas e sobre os modos de organização de seu trabalho.

Lembro, a propósito, de um episódio que vivenciei num conjunto (não universitário) que funcionava com "direção coletiva", como eu definia na época. Como quase todos os dez músicos eram autores de composições ou arranjos, a direção dos ensaios distribuía-se conforme a autoria da peça em preparo, e todos participavam com sugestões, comentários, correções. Para certas datas de apresentação, era preciso contar com a substituição de um ou mais membros, e um desses convidados ocasionais foi um saxofonista militar, que se juntou a nós exatamente num ensaio que eu organizava. Aquele músico, ao fim do ensaio, dirigiu-se a mim de forma discreta, subserviente, quase furtiva, para perguntar se eu podia "dispensá-lo" do ensaio seguinte, por conta de outro compromisso que ele havia assumido. Surpreso com a abordagem, eu respondi que ali conversávamos abertamente sobre essas coisas e que não cabia a mim dispensar nenhum dos colegas. Mas, ao mesmo tempo, fui entendendo que ele estaria acostumado com a hierarquia militar, condicionadora de seu trabalho como músico no quartel, e que aquela mesma atribuição de autoridade, que eu recebi com surpresa, era para ele o modelo "natural" da profissão.

Mas, em matéria de tornar-se músico e trabalhar com música, como sabemos, nada é natural, e não existe uma maneira única e correta de agir e pensar. Para uma educação musical que coloque em pauta valores de autonomia e cidadania - que encontramos em declarações sobre a missão de

\footnotetext{
${ }^{3}$ Cheguei a participar, por exemplo, de uma PC em que a direção estava centralizada numa parceria firmada entre um estudante, que era o compositor de todo o repertório, e um diretor musical que ele havia convidado e que não estava inscrito na disciplina. $O$ trabalho desse grupo foi apresentado não só na universidade, ao final do semestre, mas também num pequeno circuito da cidade, conforme agenda anunciada ao iniciarmos o período de ensaios.
} 
instituições do ensino superior -, parece muito adequado que a organização de conjuntos, com seus padrões de trabalho, seja um tema para a formação universitária, experimentando-se e avaliando-se em coletivo diferentes modos de operar. Do ponto de vista das competências e da flexibilidade, é mesmo interessante e desejável que estudantes aprendam a atuar em organizações musicais diversas, inclusive com margem para propor modos específicos, e até inovadores, de organizar uma prática.

Podemos acrescentar, talvez como bastante singular de uma disciplina como "Prática de Conjunto", que - numa mesma atividade curricular - se encontram disponiveis certas condições de vivência musical e de observação dessa vivência, de prática e reflexão sobre a prática, de trabalhar e teorizar sobre o trabalho.

PA: Ao afirmar que a tentativa de mapeamento que empreendemos pode servir como ferramenta de reflexão e análise sobre o fazer musical na universidade - e, principalmente, ao apontar para as possibilidades de pesquisas geridas pelos próprios alunos a partir do "campo", no caso, a própria Prática de Conjunto -, creio que você abre possibilidades de desdobramentos práticos de pesquisa a partir deste diálogo. Uma destas possibilidades seria justamente uma proposta de maior interação entre a etnomusicologia e a educação musical - campos que, a meu ver, ainda apresentam interação incipiente no Brasil. Por outro lado, certamente concordamos que este esboço de mapeamento deve ser entendido não como um tentativa de definição de modelos "certos" ou "errados", mas, sim, como matéria-prima para reflexão sobre o nosso dia a dia universitário. De forma geral, penso que ainda temos - infelizmente - pouquíssimo espaço para reflexão e para autoanálise no âmbito dos cursos universitários de música no país: os fóruns de encontro entre professores - reuniões de departamentos e colegiados - normalmente têm maior ênfase em questões burocráticas (afastamentos, comissões de matrícula, dentre outros temas) do que em questões didáticas.

Gostaria de voltar agora ao tema das Práticas de Conjunto que nascem a partir de proposições dos alunos - certamente nossa tentativa de mapeamento ficaria ainda menos completa sem uma reflexão maior sobre este tema. Creio que este tipo de PC é normalmente alvo de duas visões antagônicas: por um lado, ela pode ser compreendida como potencialmente muito rica, por permitir que os alunos tragam para a universidade seus próprios universos musicais e que desenvolvam aspectos como autonomia, criatividade, respeito à diversidade, dentre outros. Em certo sentido, a realização deste tipo de PC pode ser vista como uma espécie de "janela" que aponta na direção oposta à hierarquização implícita ao nosso sistema curricular. Por este mesmo motivo, esta prática também pode ser entendida (ainda que este pensamento não seja normalmente enunciado) como uma subversão da dicotomia tradicional professor-estudante, onde o primeiro é 
visto como agente ativo em oposição ao caráter passivo do segundo - algo que ainda tende a incomodar certos setores dos meios acadêmicos.

Talvez em decorrência desta segunda visão, a realização de PCs propostas pelos alunos esbarra em uma série de complicadores no dia a dia da universidade, como afirmamos anteriormente. Um deles diz respeito ao próprio sistema de matrículas: usualmente as inscrições em disciplinas são feitas a partir de um único sistema informático que atende a todos os cursos da universidade. Esta uniformização facilita muito as coisas do ponto de vista administrativo, mas muitas vezes ignora as especificidades de cada área. No caso da PC, o "sistema" frequentemente impede que alunos de semestres diferentes cursem uma mesma disciplina. Explico melhor: normalmente as disciplinas com mais de um semestre de duração são sequenciadas em níveis: "Harmonia I", "Harmonia II", por exemplo. Não é possivel - e nem faria sentido, pelo menos a princípio - que uma mesma turma de harmonia misturasse alunos que ingressaram em semestres diferentes, por exemplo. No entanto, se esses mesmos alunos quiserem se reunir e propor uma PC, o mais provável é que o sistema de matrícula os impeça - sob a alegação de que não se pode reunir em uma mesma disciplina alunos que estão em niveis diferentes. Porém, se isso faz sentido para a maioria das matérias, não faz sentido nenhum em termos de prática de conjunto: por que razão um aluno de oitavo período, que já cursou três semestres de PC, não pode ser agrupado na mesma disciplina de um aluno de primeiro período? Este pode ser visto como um um pequeno exemplo de como a estrutura burocrática da universidade frequentemente pode prejudicar a autonomia dos alunos que querem formar os seus próprios conjuntos musicais ${ }^{4}$.

Para além disso, a proposição de disciplinas a cada semestre é sempre prerrogativa do professor: em muitas universidades, a simples ideia de que o aluno possa propor uma PC nem é cogitada. Em outras, já existem procedimentos que permitem ao aluno solicitar a abertura de uma PC voltada para os seus interesses - normalmente há um processo de negociação com o professor que ficará responsável pela disciplina ${ }^{5}$. Mesmo com essa possibilidade, na prática verificam-se muitas resistências para a efetiva realização deste tipo de PC a cada semestre - boa parte delas relacionadas justamente com a quebra do paradigma da hierarquia professor-aluno, onde o professor detém, por assim dizer, as rédeas do curso a ser ministrado. Muitas vezes os professores não se sentem à vontade para assumir práticas

\footnotetext{
${ }^{4} \mathrm{Na}$ UNIRIO, este problema foi resolvido graças à ação coordenada de todos os professores de Prática de Conjunto, que pressionaram os serviços administrativos e conseguiram, depois de um grande esforço, quebrar esta regra. Entretanto, em um encontro nacional para debate sobre a inserção da música popular na universidade - "A Música Popular na Universidade", promovido pelo Instituto de Artes da Universidade Federal do Rio Grande do Sul (2015) -, pude constatar que o problema ainda permanece em grande parte das universidades brasileiras.

${ }^{5}$ Em algumas universidades, como é o caso da UNIRIO, o aluno pode propor a abertura de uma PC desde que apresente, com antecedência, um formulário detalhando a proposta (explicando em linhas gerais a linha de repertório e instrumentação a serem trabalhadas) e submetendo-a ao Departamento de Educação Musical.
} 
cujos repertórios eles não dominam - por razões que vão desde insegurança pessoal até uma possível má vontade em aceitar repertórios não canônicos. Outras vezes esta quebra de paradigma pode ser entendida como uma espécie de "terceirização" do trabalho do professor. Lembro-me que certa vez um aluno propôs uma prática que tinha por finalidade "testar" uma nova metodologia de ensino que ele próprio havia desenvolvido. Quando determinado professor aceitou ficar responsável pela disciplina, foi questionado pelos colegas de departamento se aquilo não seria transferir para o aluno uma responsabilidade que devia ser do professor, uma vez que toda a condução das aulas seria feita pelo estudante.

Recordo-me ainda de outros dois casos em que - ao contrário do exemplo anterior - fui eu mesmo o professor responsável pela PCs propostas pelos estudantes. Em um deles, os estudantes organizaram um grupo para trabalhar exclusivamente com o repertório de um compositor brasileiro com o qual eu não tinha qualquer familiaridade. Expliquei-lhes isso e disse que poderiamos tentar algo como uma "direção coletiva". Eles se empenharam na pesquisa de repertório e na criação dos arranjos, e eu os ajudei a conduzir os ensaios - e a fazer com que eles próprios ganhassem autonomia para que se organizassem. O resultado foi excelente, com uma bela apresentação ao final do semestre. Mas já tive outro caso em que fui procurado por estudantes que queriam fazer uma prática com base na música de Cabo Verde. Apesar de conhecer muito pouco esta música, disse-lhes que poderiamos pensar em uma pesquisa coletiva que servisse de base para a construção de um repertório e de arranjos a serem geridos coletivamente. Acabou não dando certo: os alunos não conseguiram se organizar nem manter a assiduidade na $\mathrm{PC}$, e o resultado foi não haver apresentação final.

Mesmo com todos esses problemas, penso que esse tipo de prática deveria ser cada vez mais estimulada, pelas reais possibilidades de enriquecimento acadêmico - em niveis musicais e humanos - que ela contém. Não se trata, mais uma vez, de definir este tipo de PC como "melhor" do que as outras, ou de defini-la como um padrão ideal a ser utilizado universalmente, mas, sim, de assegurar suas condições de existência dentro deste "ecossistema" tão variado de possibilidades de práticas musicais.

JAS: Pensando aqui sobre a "Prática de Conjunto" como atividade curricular em cursos de Música, e referindo a experiências numa IES do Rio de Janeiro, supomos que existam semelhanças com cursos em outros estados. Mas também existirão particularidades e iniciativas que educadores e estudantes podem levantar. Novos apontamentos encorpariam uma reflexão sobre o que está sendo feito, no rumo de uma teorização mais geral sobre os problemas e as possibilidades de "enriquecimento acadêmico", que você indica estarem presentes nessa via.

Ao fim desta reflexão inicial, portanto, o que dissermos será provisório e estará também temperado por nossa visão de educação. Dito isto, podemos 
esboçar uma ou mais hipóteses sobre os efeitos da PC para uma formação universitária? Percebo alguns momentos de convergência no diálogo e, dentre eles, está a sugestão de que um possivel ganho para os estudantes principalmente nos casos em que se exercite uma autogestão - seja uma aprendizagem organizacional, o desenvolvimento de competências para organizar e manter um conjunto, em suas diversas ações e tarefas.

Nessa hipótese, estamos tratando de algo relevante para a sustentação profissional de uma ação musical em coletivo; ao mesmo tempo, ficaria mais explícita a abordagem de valores éticos e políticos cujo desenvolvimento também nos parece relevante - falamos em autonomia, e, numa reunião que fizemos para tratar do texto, falamos da relação "empoderamento do estudante $v s$. burocracia”. E, por esse ângulo, que corresponde a uma visão determinada de educação, é preciso reconhecer que nem todas as "práticas de conjunto", com suas diferenças de orientação pedagógica, propõem como objetivo fomentar esses valores.

Teorizar sobre uma prática educativa é sempre útil para assegurar suas condições de existência e para solucionar problemas, num investimento continuado que atravessa os currículos e suas reelaborações. Pelo menos dois caminhos de teorização são possivveis. Um segue pelo ponto de vista do(a) educador(a), como experimentamos agora, em tom de hipótese: na educação universitária, as atividades de PC trariam para estudantes, além de saberes técnicos, outros ganhos - e aqui mencionamos: autonomia, competências para o trabalho em coletivo etc. Outro caminho é o da investigação etnográfica, baseado em observação, participação e interlocução com os sujeitos que atuam nessas práticas, estudando e fazendo música. Por essa via, aquilo que acontece entre pessoas, aquilo que fazem e dizem, passaria para uma posição mais central. E, como você tocou na relação entre etnomusicologia e educação musical, eu aproveito para ressaltar esse ponto metodológico: se, por um lado, na tradição dos relatórios de pesquisa dessas áreas, a gente acaba conhecendo mais sobre o ponto de vista, a análise e a interpretação de educadores e etnógrafos, por outro lado, numa tendência mais recente, vemos sinais e propostas de que o próprio trabalho acadêmico tem muito a ganhar na medida em que investigarmos e publicarmos com maior participação dos sujeitos - praticantes, estudantes de música -, conhecendo-se mais sobre o ponto de vista, a análise e a interpretação desses sujeitos.

PA: Creio que você sintetizou todos os pontos importantes deste diálogo, bem como seus possiveis desdobramentos em pesquisas futuras. As duas hipóteses apresentadas são bastante instigantes e certamente nos motivam a "colocar a mão na massa" - fico desde já tentado a propor, por exemplo, uma $\mathrm{PC}$ onde os alunos sejam convidados a fazerem observações de campo que possam gerar futuras pesquisas. Ou a propor parcerias entre professores de etnomusicologia e professores de prática de conjunto, por exemplo... 
Para além destas duas hipóteses de trabalho, creio que fica a constatação de que é preciso se pensar cada vez mais na prática de conjunto como uma disciplina-chave na formação superior em música. Sua importância tem relação direta, a meu ver, com a sua capacidade de assumir múltiplas formas - uma disciplina "coringa", capaz de refletir, em microcosmo, toda a complexidade e variedade de fazeres musicais exteriores aos muros da academia e ao mesmo tempo de proporcionar vivências sonoras e sociais que se tornam cada vez mais escassas no chamado "ambiente de mercado". Uma disciplina que potencialmente pode quebrar hierarquias entre professores e alunos e se constituir como "janela" para a entrada de outros saberes não previstos nos currículos, mas que também pode ser engessada de todas as formas pela burocracia universitária. Uma disciplina que pode evidenciar a alteridade entre alunos e professores provenientes de diferentes "tribos" sociais e musicais, mas que também pode ser a melhor maneira de superar tais diferenças. Uma disciplina presente - com variações de nome - em praticamente todas as instituições de ensino superior de música do país e que, sendo tão "universitária", tem também o poder de transpor os muros desta mesma universidade, levando conhecimentos musicais a públicos mais amplos através de apresentações abertas.

Finalmente, penso que a PC pode ser apontada como a disciplina universitária que melhor simbolizaria a "paixão musical", no sentido que Hennion (2002) dá a este termo. Para este autor, a literatura musicológica seria dividida por espécie de "cunha" entre duas direções de análise: aquelas que aceitam e comentam o objeto musical e aquelas que o impugnam e tentam remeter seu "estranho poder" às suas determinações sociais. Desta forma, sua proposta de sociologia da paixão musical tentaria ir para além desta dicotomia, trazendo de novo ao centro do debate os atores sociais (músicos, público, apreciadores, dentre outros) que atuam como mediadores entre estes dois extremos. Neste sentido, a PC em contexto universitário pode e deve ser estudada como um grande laboratório, onde esta paixão musical simboliza não apenas o prazer de tocar um instrumento ou de cantar em conjunto, como também toda a gama de sentimentos envolvidos nas coletividades humanas. Seu estudo, portanto, inclui não só uma diversidade de campos de saberes em música - práticas interpretativas, educação musical, etnomusicologia, sociologia da música -, como o desafio de lidar academicamente com algo tão subjetivo como a paixão das pessoas ao produzirem música.

\section{REFERÊNCIAS}

ARAÚJO, Samuel. Conflict and Violence as Theoretical Tools in Present-Day Ethnomusicology: Notes on a Dialogic Ethnography of Sound Practices in Rio de Janeiro. Ethnomusicology, v. 50, n. 2, p. 287-313, 2006.

ARROYO, Margarete. Um olhar antropológico sobre práticas de ensino e aprendizagem muslcal. Revista da ABEM, v. 8, n. 5, p. 13-20, 2000. 
BAKHTIN, Mikhail M. The problem of speech genres. In: EMERSON, Caryl; HOLQUIST, Michael (Eds.). Speech Genres and Other Late Essays. Austin: Texas University Press, 1987.

BAREMBOIM, Daniel; SAID, Edward. Parallels and paradoxes - explorations in music and society. London: Bloomsbury Books, 2002.

BOURDIEU, Pierre. The Logic of Practice. Cambridge: Polity Press, 2002.

FREIRE, Paulo. Pedagogia do Oprimido. São Paulo: Paz e Terra, 1970.

FUX, Johann Joseph. Gradus ad Parnassum. Alfred Mann (ed.). New York: Norton, 1971.

GREEN, Lucy. How popular musicians learn: a way ahead for music education. Washington: Ashgate, 2001.

GREEN, Lucy. Music, informal learning and the school: a new classroom pedagogy. Washington: Ashgate, 2008.

HENNION, Antoine. La passion musicale. Barcelona: Ediciones Paidós Ibérica, 2002.

KEIL, Charles; FELD, Steven. Music Grooves. Chicago: University of Chicago Press, 1994.

NZEWI, Meki Emeka. Educação Musical sob a perspectiva da diversidade cultural e globalização: posição da CIIMDA. Revista da ABEM, Londrina, v. 20, n. 28, p. 81-93, 2012.

PRASS, Luciana. Maçambiques, Quicumbis e Ensaios de Promessa: um reestudo etnomusicológico entre quilombolas no sul do Brasil. Tese (Doutorado em Música) - Programa de Pós-Graduação em Música, Universidade Federal do Rio Grande do Sul, 2009.

QUEIROZ, Luis Ricardo Silva. Educação musical e cultura: singularidade e pluralidade no ensino e aprendizagem da música. Revista da $A B E M$, v. 12, n. 10, p. 99-110, 2004.

SALGADO, José Alberto. Construindo a profissão musical: uma etnografia entre estudantes universitários de Música. Tese (Doutorado em Música) Programa de Pós-Graduação em Música, Universidade Federal do Estado do Rio de Janeiro, 2005.

SALGADO, José Alberto; GANC, David; ERTHAL, Júlio; PERES, Leonardo Rugero; GREGORY, Jonathan. Refletindo sobre a interlocução em pesquisas com música. Debates, Rio de Janeiro, n. 12, p. 93-105, 2014.

SANTOS, Cristina Bertoni dos. Aula de música e escola: concepções e expectativas de alunos do ensino médio sobre a aula de música da escola. Revista da ABEM, Londrina, v. 20, n. 27, p. 79-92, 2012. 
SCHAFER, R. Murray. O ouvido pensante. São Paulo: Editora da UNESP, 1991.

TRAVASSOS, Elizabeth. Apontamentos sobre estudantes de música e suas experiências formadoras. Revista da ABEM, Porto Alegre, v. 13, n. 12, p. 11$19,2005$.

José Alberto Salgado e Silva é Professor Associado na Escola de Música da Universidade Federal do Rio de Janeiro, e integra o corpo docente dos Programas de Pós-graduação em Música da UFRJ (PPGM-UFRJ) e da UNIRIO (PPGM-UNIRIO). É Professor Visitante na Universidade de Aveiro e Investigador colaborador do INET-md (Portugal). Leciona disciplinas e orienta pesquisas em educação musical e etnomusicologia desde a conclusão do mestrado (Music Education, IoE-UL). Sua pesquisa de doutoramento examinou processos de profissionalização, com estudantes universitários de Música, noRio de Janeiro. O trabalho musical e a educação universitária são tematizados nos cursos que leciona, em projetos de pesquisa e em artigos e comunicados, entre eles "Acomposição como prática regular em cursos de música" (2001), "Uma análise dasperspectivas de estudantes sobre o estudo de música na universidade" (2006) e "Questões de método e interlocução em pesquisas com práticas de música" (2014).

Pedro Aragão é Professor na Universidade do Rio de Janeiro (UNIRIO), Brasil, onde atua na graduação - lecionando prática de conjunto e História da Música Popular Brasileira - e na pós-graduação. Seus interesses de pesquisa incluem música popular brasileira, arquivos sonoros, relações entre indústria fonográfica e música popular e lusofonia. Atualmente é também investigador colaborador do INET-md (Portugal). 